\title{
Excavation of the Internet of Things in Urban Areas Based on an Intelligent Transportation Management System
}

\author{
Febronie Nambajemariya, Yongshun Wang* \\ School of Electronics and Information Engineering, Lanzhou Jiaotong University, Lanzhou, China \\ Email: hnana1007@mail.com, ${ }^{*}$ wangysh@mail.lzjtu.cn
}

How to cite this paper: Nambajemariya, F. and Wang, Y.S. (2021) Excavation of the Internet of Things in Urban Areas Based on an Intelligent Transportation Management System. Advances in Internet of Things, 11, 113-122.

https://doi.org/10.4236/ait.2021.113008

Received: May 21, 2021

Accepted: July 4, 2021

Published: July 7, 2021

Copyright $\odot 2021$ by author(s) and Scientific Research Publishing Inc. This work is licensed under the Creative Commons Attribution International License (CC BY 4.0).

http://creativecommons.org/licenses/by/4.0/

\begin{abstract}
Transportation, as one of the most common aspects people use in their daily lives, has resulted in highly complex traffic in urban areas due to the large number of private vehicles. As some results of the traffic congestion, there is energy consumption, environmental pollution, unplanned accidents, and time is wasted due to congestion and traffic jams. With the aid of the Internet of Things (IoT), which is an excellent computerized technology solution for all field claims, Internet of Things (IoT) technology has recently provided an efficient and effective traffic management system, especially in transportation, due to the combined functions IoT can handle, there are management, monitoring, tracking, identifying, computing, and so on. This article provided a comprehensive overview of a variety of intelligent management systems that have been built using IoT to alleviate traffic congestion.
\end{abstract}

\section{Keywords}

Internet of Things (IoT), Intelligent Traffic, Traffic Congestion,

Traffic Management

\section{Introduction}

In recent years, urban transportation has become more complicated and congested as a result of the popularity and use of private transportation by civilians all over the world. This has resulted in severe traffic congestion during peak hours, highlighting the importance of a well-functioning traffic management system in order to prevent collisions, emissions, and time waste [1]. The Internet of Things (IoT) seems to be gaining popularity. The Internet of Things (IoT) is a new smarter technology that has contributed to transportation during traffic management through cloud use and proper tracking using various machine 
learning methods. Traffic management systems that are efficient and reliable help to reduce traffic congestion.

\section{Literature Riview}

\subsection{Intelligent Traffic System}

Existing signal system lacks the technology to handle the traffic in efficient way Authors mentioned in [2] Using IoT they have proposed a system that use of different sensors which can be deployed on the roadside for collecting data regarding congestion which will be further processed by the micro controller situated on the traffic signal higher priority for emergency vehicles like Ambulance such that the lane that contains emergency vehicle would go first until emergency vehicle passes. A hybrid approach in [3] is used to optimize traffic flow on roads and an algorithm is devised to manage various traffic situations efficiently. The authors create a system that uses data from cameras and sensors to calculate traffic density and then adjusts traffic signals. During a traffic jam, the authors employed an algorithm based on Artificial Intelligence to forecast future traffic density and to decrease traffic congestion. They also utilized RFID to prioritize emergency vehicles such as ambulances and fire trucks. The authors also considered what would happen if there was a fire on the road, and how they would handle it. Smoke sensors were employed as part of the system to identify this circumstance. The efficiency of the suggested traffic management system has been shown by the authors using a prototype that not only optimizes traffic flow but also connects adjacent rescue departments to a centralized server.

\subsection{Advanced Traffic Management System}

The existing traffic prediction methods mostly dedicated to highway and urban traffic management, and limited studies focused on collector roads and closed campuses Authors said in [4] where they have proposed an IoT based system model to collect, process, and store real-time traffic data for such a scenario. The system's main purpose was to increase mobility by providing real-time traffic updates on traffic congestion and odd traffic events via roadside messaging devices. The suggested technology might send out early warning signals to citizens, allowing them to save time, especially during peak hours. The device also transmits updates from the administrative authorities on traffic. With a Context of Bangladesh in [5] proposed a real-time traffic management system (TMS) using the Internet of Things (IoT) and data analytics. Ultrasonic sensors were used to detect traffic density, and after analyzing the sensor data, the system controller controlled the traffic signal timing using a traffic management algorithm, as well as sending data to a cloud server via a Wi-Fi module. As the authors pointed out, if an emergency vehicle is recognized, the proposed system offers priority, i.e. long signal duration, to pass through the intersection. If a car violates a traffic light, the system can identify it and issue a fine, which is paid through the Traffic Wallet smartphone app. This proposed system is low-cost, easy-to-install, and simple-to-maintain. 


\section{Internet of Things}

The Internet of Things (IoT) is a paradigm in which objects with sensors, actuators, and processors interact with one another to accomplish a goal. About $85 \%$ of networks are disconnected and don't exchange data with one another or the cloud, The Internet of Things (IoT) is one such technology that enables interconnection and also refers to making devices smarter by linking them online to acquire and process data, as mentioned by Authors in [6]. The basic concept of creating IoT architecture is to make the machine self-reliant while also being connected to a web server for signal reception. The Internet of Things (IoT) has now reached all corners of the globe is essentially a physical-digital interaction [7]. A plethora of sensors and actuators communicate between the digital and physical worlds as Figure 1(a) describe and Figure 1(b) give a deep understanding of how Sensors, actuators, and processors are used in IoT products.

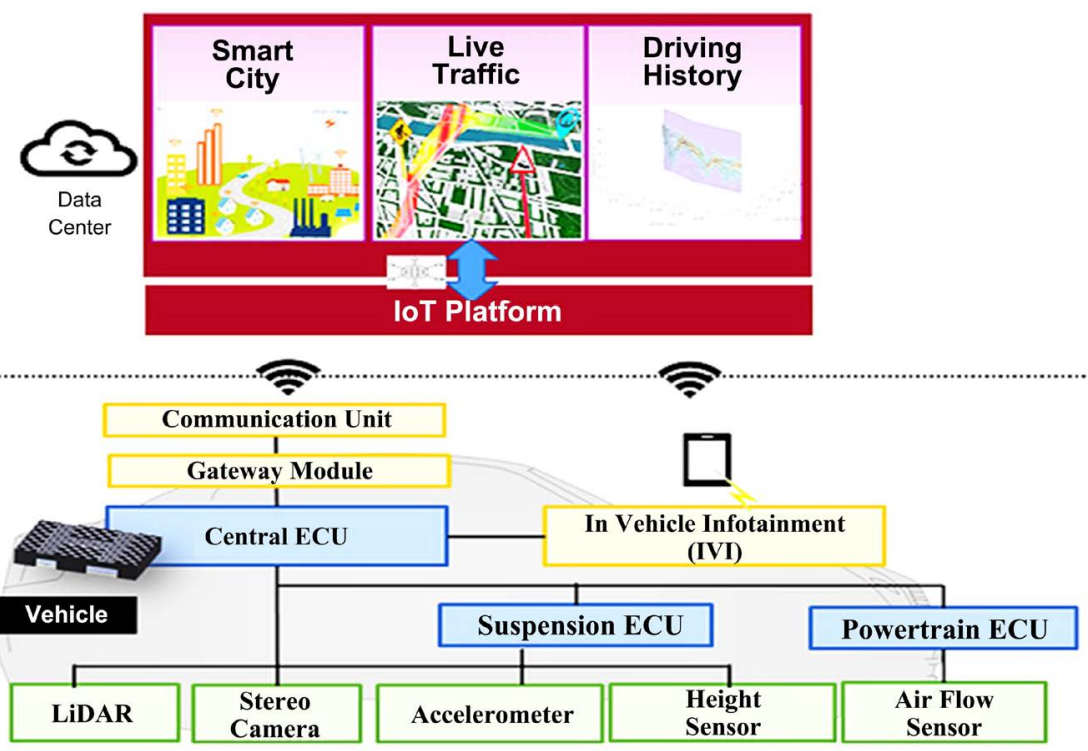

(a)

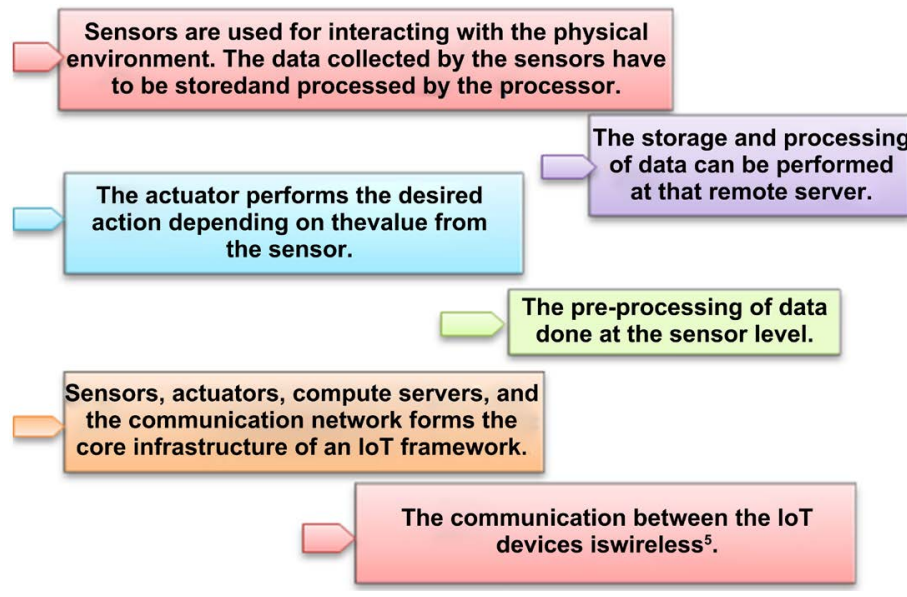

(b)

Figure 1. (a) IoT platform; (b) IoT platform. 


\subsection{Background on IoT Components in Vehicles}

Vehicles of past year's technology was not more developed compared with today's technology as SAE has described in vehicle's levels, where a digital revolution in the 21st century is in form of connected and autonomous vehicle (vehicle to everything, which includes vehicle-to-vehicle, vehicle-to-infrastructure, vehicle-to-network, vehicle-to-cloud, vehicle-to-device and vehicle-to-pedestrian), and we are living in such kind of digital because of integration of Internet of Things (IoT) components have been applied into vehicles day to day as shown in Figure 2. They become part of a network. Vehicles can communicate with each other, with the surrounding infrastructure and with other drivers. Gradually the technologies of IoT in vehicles assisted driving (steering, acceleration and brake support) which help to decrease different problems in transportation [6]. As the technology in vehicle increase as the transportation issues decrease the international Society of Automotive Engineers (SAE) helped to describe the technology in vehicles using levels on Figure 3.

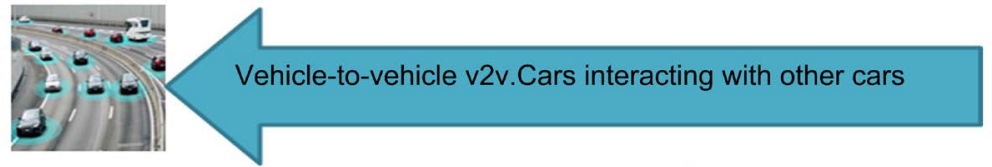

Vehicle-to-Infrastructure V2i.cars interacting with roads or external obiects

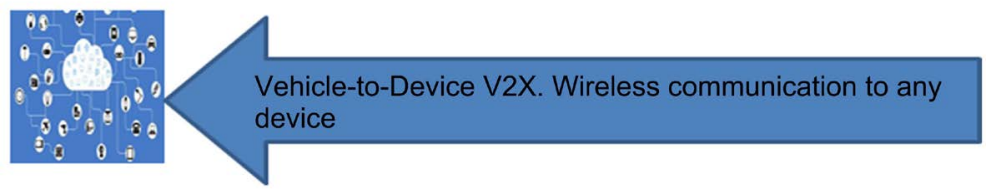

Figure 2. Categories of connectivity based IoT.
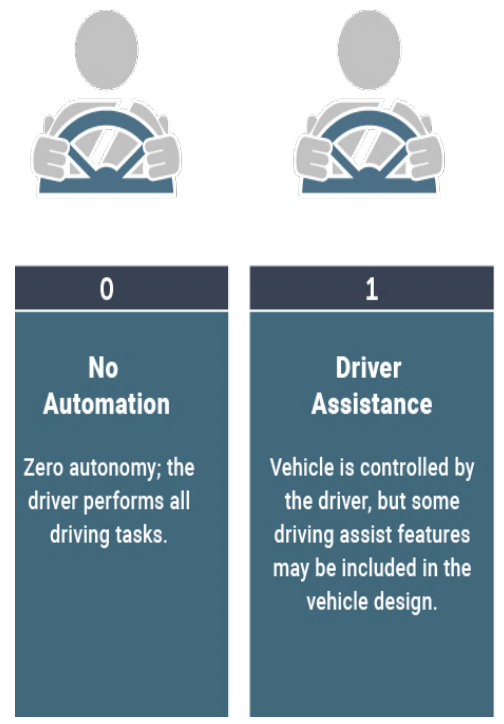
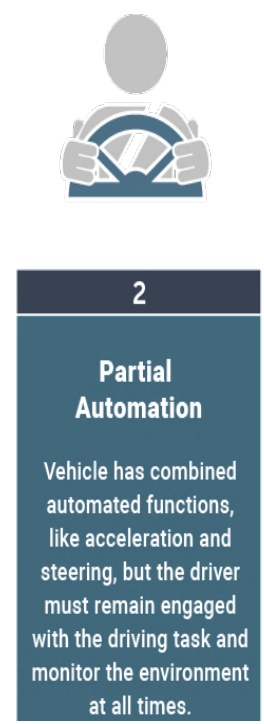
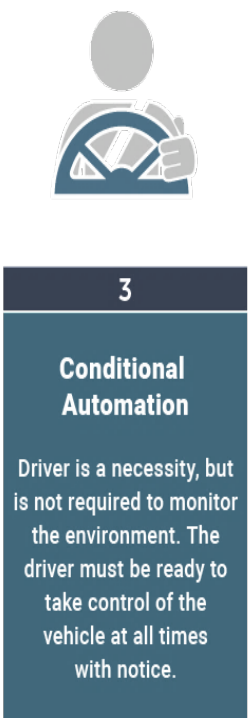
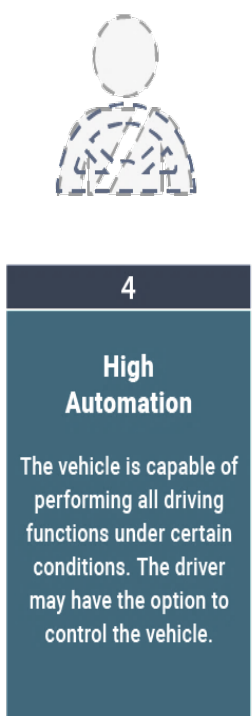
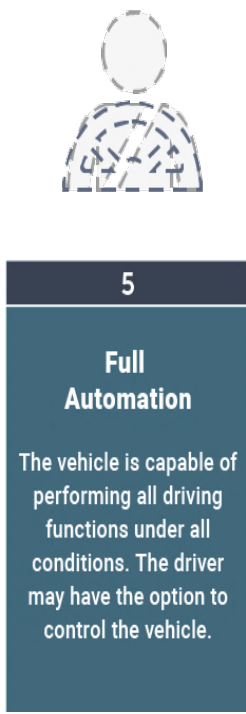

Figure 3. Connected and autonomous vehicle levels [8]. 


\subsection{Ways IoT Is Transforming Transportation Management}

The Internet of Things (IoT) is transforming our lives at a breakneck rate. Environmental monitoring and transportation networks are two areas where the Internet of Things finds use. This is particularly true in the automotive industry, which is home to some of the most significant inventions [9]. Here are some of the biggest ways the IoT is transforming the automotive industry and our roads [10]:

$>$ The way people drive

Reduce pollution and energy

Improving road safety

Solve traffic congestion in cities

Expenditure

Lead to better roads

Environment applications

Mobility applications

\subsection{Intelligent Traffic Management System}

As shown in Figure 4, an intelligent traffic management system based on IoT can be divided into three groups. This refers to a range of tools such as traffic engineering principles, software, hardware, and communication technologies that can be applied to the transportation system in an integrated manner to enhance its efficiency and safety. Table 1 discusses various methods of traffic and vehicle monitoring and control several techniques and methods are based on internet of things (IoT) approaches, as seen in Figure 5. For future Enhancement in Intelligent Transportation Management system Table 2 gives the inclusive outlook of few recent research articles in the intelligent traffic management system based on internet of things (IoT).

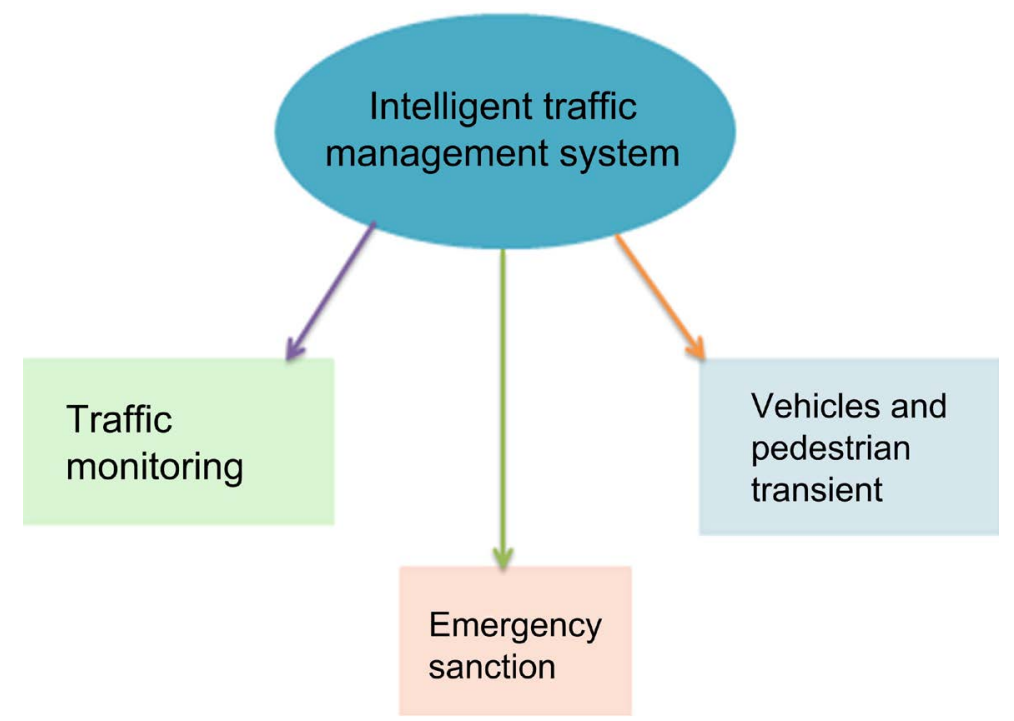

Figure 4. Intelligent traffic management system block. 
Table 1. Technology and performance parameters used in transportation using IoT.

\begin{tabular}{|c|c|c|c|c|}
\hline No & System & Performance parameters & Performed work & Applications \\
\hline & $\begin{array}{l}\text { Intelligent Traffic Information } \\
\text { System [11] [12] }\end{array}$ & $\begin{array}{l}\text { Infrared Ray Sensor, RFID, } \\
\text { Wireless Sensor Networks; } \\
\text { Agent Technology }\end{array}$ & $\begin{array}{l}\text { The paper proposes an architecture that combines internet of } \\
\text { things and agent technology into a single framework, with the } \\
\text { agent technology handling effective communication and } \\
\text { interfaces among a large number of heterogeneous, highly } \\
\text { distributed, and decentralized IoT devices }\end{array}$ & Smart City \\
\hline
\end{tabular}

Development of the Flexible Lab view, Arduino Board,

Traffic Control System

Thing Speak, HTTP and

2 Using the Lab View and Thing MQTT Protocols, MATLAB Speak

[13]

3

Intelligent Transportation

System [14] [15]

\section{WSN, an Active}

Radio-Frequency Identification (RFID), and IoT

Intelligent Traffic Congestion

Control System/IoT Based

Ultrasonic Sensor Node

(USN), Wi-Fi. Traffic Density Sets the signal operating time dependent on traffic congestion

4 Intelligent Traffic Signal Syste for Emergency Vehicles [16] [11]

5 An Intelligent Traffic and

5 Vehicle Monitoring System

ATMEGA, GPS, IoT, Traffic Management, Ublox-Neo 6M, Zigbee, RFID, Bluetooth Intelligent Transportation System.

Intel Galileo Gen 2 Board,

An IoT-VANET-Based Traffic

6 Management System for Arduino Duemilanove Board, Emergency Vehicles in a Smart Wyliodrin IDE Studio,

The Raspberry Pi, Arduino board, and webcams are among the lower-level hardware used. The HW model is built City [18]

IoT-Based Traffic

7 Management System for Ambulances

Intelligent Traffic Monitoring/ An Internet of Things (IoT)

8 based Smart Traffic

Management System:

A Context of Bangladesh [5]

Automated Traffic System Pedestrian Safe Smart Crossing

9 System/Internet of Things Network Cognition and Traffic Management System [21]

10 Car Parking System

11 Traffic Monitoring System [24]
Arduino UNO, GPS neo 6M and SIM 900A

OWL Urban Traffic System (UTS), Granular Computing, Ubiquitous Computing [20]

Sensors, CCTV, Fuzzy logic

Internet of Things (IoT) Autonomous Car Parking, Arduino, ESP8266 Wi-Fi Module, Ultrasonic Sensors [23]

KNN Algorithm, IoT RFID · GSM [25] around road marking requirements. The MATLAB help in Thing Speak is pre-installed

The internet of things was combined with agent technology to create a single platform that handled effective communication and interfaces among a large number of heterogeneous,

highly distributed, and decentralized devices within the IoT

The monitoring module uses an ATMEGA series

Microcontroller, while the tracking module uses a NodeM-

CU. They've also set up a cloud data stream with the alias

"mtech track" and used it to publish the data [17]

The system is linked to the internet, allowing for continuous

monitoring of the various lanes. From a single location, the

data collected from various lanes is examined and monitored

Traffic

Congestion

Traffic

Congestion System

Traffic

Congestion

An Arduino-based traffic control system for healthcare-related emergencies was developed, with $12 \mathrm{~V}, 1 \mathrm{~A}$ power for the GSM SIM 900A and $10 \mathrm{~V}$ for the Arduino UNO incorporated into the ambulance, with power supplied from the fuse board

Traffic

Control to make a path to one or more ambulances

The Zigbee Protocol is used to decide the concentration of traffic. Web 2.0 services are used to connect traffic light clusters and road information

Road Traffic

For an efficient smart city traffic management, propose smart pedestrian crossing management at traffic light junctions using a fuzzy based approach

Traffic Congestion

In conjunction with an ultrasonic sensor

The Internet of Things (IoT) is used. Wi-Fi is used to transmit sensor data

ESP8266 module for any open source IoT platform that is

Car Parking

simple to use

To view data, HTTP is used

Within three major areas, TMS uses multiple IRs in an IoT model using the KNN algorithm:

1) Android Software

2) Communication on the server side

3) User Interaction 


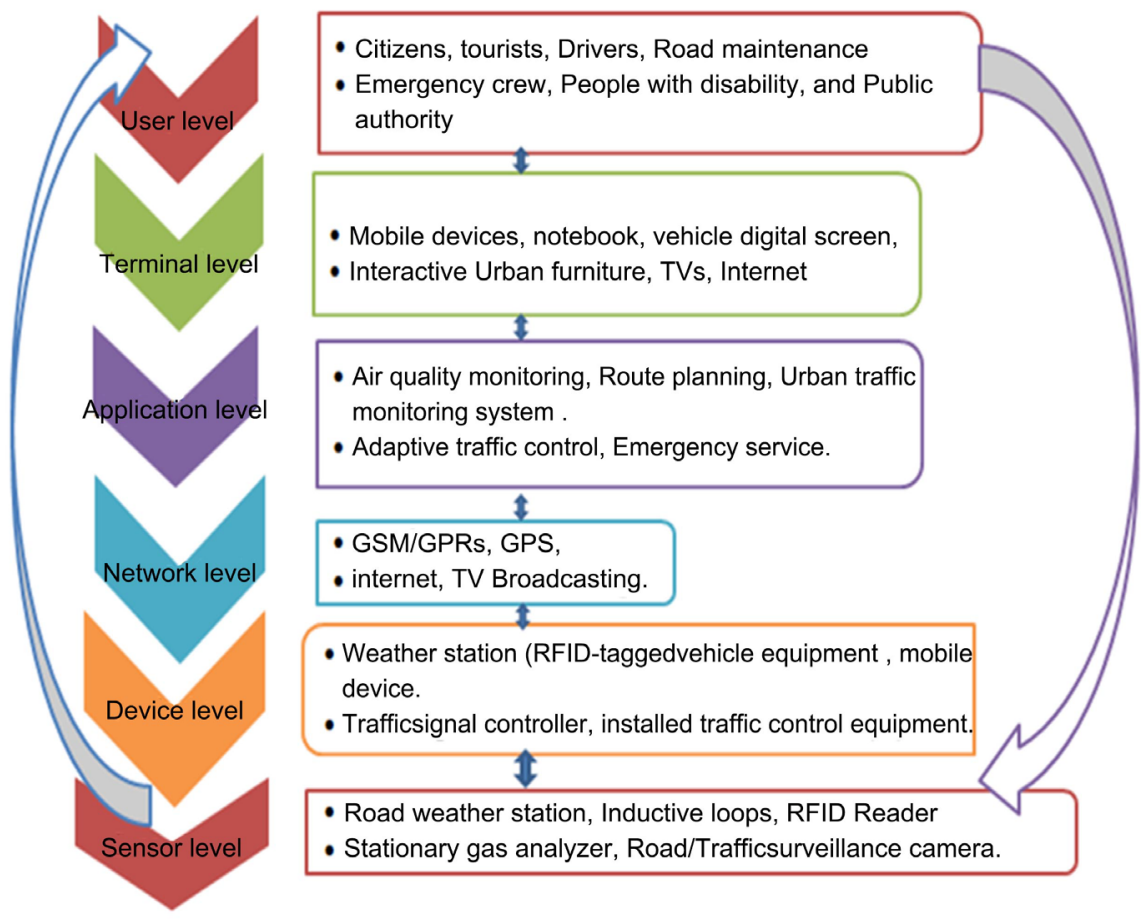

Figure 5. IoT approach for traffic management.

\section{Future Anhancement in Intelligent Transportation Management System}

Table 2. Future anhancement in intelligent transportation management system.

\begin{tabular}{|c|c|c|c|}
\hline No & Title & Author's name & Future anhancement \\
\hline 1 & $\begin{array}{l}\text { Development of the Flexible Traffic } \\
\text { Control System Using the Lab View and } \\
\text { Thing Speak. }\end{array}$ & $\begin{array}{l}\text { Anatoliy Sachenko, Maciej Dobrowolski, } \\
\text { Oleksandr Osolinskyi, Volodymyr } \\
\text { Kochan, Pavlo Bykovyy (2020) }\end{array}$ & $\begin{array}{l}\text { The analysis of function separation between the } \\
\text { microcomputer and the cloud in order to choose the } \\
\text { best set of functions for each device component. }\end{array}$ \\
\hline 2 & $\begin{array}{l}\text { Intelligent Design and Implementation } \\
\text { of Blockchain and Internet of Things- } \\
\text { Based Traffic System. }\end{array}$ & $\begin{array}{l}\text { Qilei Ren, Ka Lok Ma, Muqing Li, } \\
\text { Bingjie Gao and Jieming Ma (2019) }\end{array}$ & $\begin{array}{l}\text { How to boost the efficiency of running a blockchain- } \\
\text { based system on a low-power embedded system, and } \\
\text { how to address the shortcomings of blockchain smart } \\
\text { contracts that could improve the system's expandability. }\end{array}$ \\
\hline 3 & $\begin{array}{l}\text { Implementation of IoT Based Intelligent } \\
\text { Transportation System }\end{array}$ & Arun. V and Dr. M. Poongothai (2018) & $\begin{array}{l}\text { It considers adding other sensors to the mobile } \\
\text { propagation node, such as proximity sensors at college } \\
\text { transportation stops and in the passenger seat, and } \\
\text { connecting them to the Internet of Things. Using the } \\
\text { Big Data approach, it will also be important to develop } \\
\text { models for analyzing data that the monitoring system } \\
\text { offers. }\end{array}$ \\
\hline 4 & $\begin{array}{l}\text { A vehicular Network-Based Intelligent } \\
\text { Transport System for Smart Cities }\end{array}$ & $\begin{array}{l}\text { Tayyaba Zaheer, Asad Waqar Malik, } \\
\text { Anis Ur Rahman, Ayesha Zahir and } \\
\text { Muhammad Moazam Fraz (2019) }\end{array}$ & $\begin{array}{l}\text { To test a hybrid solution that combines the use of } \\
\text { RSUs and/or a central server to store traffic data using } \\
\text { the Internet and physical infrastructure. }\end{array}$ \\
\hline 5 & $\begin{array}{l}\text { IoT Based Intelligent Transportation } \\
\text { System (IoT-ITS) for Global } \\
\text { Perspective: A Case Study }\end{array}$ & $\begin{array}{l}\text { S. Muthuramalingam, A. Bharathi, } \\
\text { S. Rakesh kumar, N. Gayathri, } \\
\text { R. Sathiyaraj and B. Balamurugan (2019) }\end{array}$ & $\begin{array}{l}\text { In the current road situation, to deal with the applied } \\
\text { energy conservation process in ITS and the efficiency } \\
\text { scheme. }\end{array}$ \\
\hline 6 & $\begin{array}{l}\text { An IoT based Intelligent Traffic Congestion } \\
\text { Control System for Road Crossings }\end{array}$ & Pampa Sadhukhan, Firoj Gazi (2018) & $\begin{array}{l}\text { The output of this proposed congestion management } \\
\text { system will be evaluated using a test bed. }\end{array}$ \\
\hline
\end{tabular}




\section{Continued}

Applying the IoT Platform and Green

7 Wave Theory to Control Intelligent Traf

7 fic Lights System for Urban Areas in

Vietnam

Software Defined Network-Based Con-

8 trol System for an Efficient Traffic Management for Emergency Situations in Smart Cities Internet of Things Network Cognition and Traffic Management System

An Innovation Model for Smart Traffic 10 Management System Using Internet of Things (IoT)

IoT-Based Traffic Management System for Ambulances

An IoT-VANET-Based Traffic

12 Management System for Emergency Vehicles in a Smart City
1) A method of implementing the framework for a

Cao Tho Phan, Duy Duong Pham, Hoang network of arterial roads common in large cities.

Vu Tran, Trung Viet Tran and Phat $\quad$ 2) A real-world evaluation in a dynamic urban setting Nguyen Huu (2019) should be conducted to assess the system's reliability and effectiveness.

Albert Rego, Laura Garcia, Sandra Sendra, Jaime Lloret (2018)

IoT networks could benefit from the addition of cameras or other detection systems, and the SDN network could benefit from the addition of a detection system.

Abida Sharif, Jian Ping Li, Muhammad Irfan Sharif (2018)

IoT algorithms should be implemented in big data and IoT security systems.

The proposed model, which is intelligent and

Amardeep Das, Prasant Dash and Brojo

Kishore Mishra (2018)

future-oriented, uses transportation scheduling methods to identify the packages of interventions that can better achieve goals.

Mohammad Moazum Wani, Samiya

Khan, Mansaf Alam

Sensor-based patient data collection modules and the planned system's integration.

Lucy Sumi and Virender Ranga (2018) other malicious intent can be a difficult job.

\section{Conclusion}

This research paper provides a comprehensive overview of the intelligent traffic system based on the Internet of Things (IoT), its benefits and drawbacks in terms of real-time analysis of traffic congestion, pedestrian crossings, and free path availability for emergency vehicles in urban areas, as well as its future development toward intelligent traffic regulations and alert systems for vehicles.

\section{Conflicts of Interest}

The authors declare no conflicts of interest regarding the publication of this paper.

\section{References}

[1] Dubey, A. and Lakhani, M. Management System as a Part of Intelligent.

[2] Toshniwal, A., Bhaskar, S., Doshi, S., Vaity, K. and Bandekar, P.A. (2018) Traffic Congestion Management and Monitoring in IoT. International Journal for Scientific Research and Development, 6, 2321-0613. http://ijsrd.com/

[3] Javaid, S., Sufian, A., Pervaiz, S. and Tanveer, M. (2018) Smart Traffic Management System Using Internet of Things. 2018 20th International Conference on Advanced Communication Technology (ICACT), Chuncheon, 11-14 February 2018, 393-398. https://doi.org/10.23919/ICACT.2018.8323770

[4] Sarrab, M., Pulparambil, S. and Awadalla, M. (2020) Development of an IoT Based Real-Time Traffic Monitoring System for City Governance. Global Transitions, 2, 230-245. https://doi.org/10.1016/j.glt.2020.09.004

[5] Kadar, A. and Masum, M. (2018) An Internet of Things (IoT) Based Smart Traffic Management System: A Context of Bangladesh. 2018 International Conference on Innovations in Science, Engineering and Technology (ICISET), Chittagong, 27-28 
October 2018, 418-422. https://doi.org/10.1109/ICISET.2018.8745611

[6] Lu, Q., Tettamanti, T., Hörcher, D., Varga, I. and Q. Lu, (2020) The Impact of Autonomous Vehicles on Urban Traffic Network Capacity: An Experimental Analysis by Microscopic Traffic Simulation Experimental Analysis by Microscopic Traffic Simulation. Transportation Letters, 12, 540-549. https://doi.org/10.1080/19427867.2019.1662561

[7] Subrahmanyam, V. and Aruna, K. (2018) Future Automobile an Introduction of IoT. International Journal of Trend in Research and Development, 5-8.

[8] Watch, P. (2020) Advanced Technologies for Industry-Product Watch. IoT Components in Connected and Autonomous Vehicles.

[9] Aris, I.B., Sahbusdin, R.K.Z. and Amin, A.F.M. (2015) Impacts of IoT and Big Data to Automotive Industry. 2015 10th Asian Control Conference (ASCC), Kota Kinabalu, 31 May-3 June 2015, 1-5. https://doi.org/10.1109/ASCC.2015.7244878

[10] Jadaan, K., Zeater, S. and Abukhalil, Y. (2017) Connected Vehicles: An Innovative Transport Technology. Procedia Engineering, 187, 641-648. https://doi.org/10.1016/j.proeng.2017.04.425

[11] Sadhukhan, P. and Gazi, F. (2018) An IoT Based Intelligent Traffic Congestion Control System for Road Crossings. 2018 International Conference on Communication, Computing and Internet of Things (IC3IoT), Chennai, 15-17 Februray 2018, 371-375. https://doi.org/10.1109/IC3IoT.2018.8668131

[12] Yogheshwaran, M., Praveenkumar, D., Pravin, S., Manikandan, P.M. and Saravanan, S. (2020) IoT Based Intelligent Traffic Control System. International Research Journal of Engineering and Technology (IRJET), 7, 59-63.

[13] Sachenko, A., Osolinskyi, O., Bykovyy, P., Dobrowolski, M. and Kochan, V. (2020) Development of the Flexible Traffic Control System Using the Lab View and Thing Speak. 2020 IEEE 11 th International Conference on Dependable Systems, Services and Technologies (DESSERT), Kyiv, 14-18 May 2020, 326-330.

https://doi.org/10.1109/DESSERT50317.2020.9125036

[14] Hawi, R., Okeyo, G. and Kimwele, M. (2018) Smart Traffic Light Control Using Fuzzy Logic and Wireless Sensor Network. 2017 Computing Conference, London, 18-20 July 2017, 450-460. https://doi.org/10.1109/SAI.2017.8252137

[15] Saifuzzaman, M., Moon, N.N. and Nur, F.N. (2018) IoT Based Street Lighting and Traffic Management System. 2017 IEEE Region 10 Humanitarian Technology Conference (R10-HTC), Dhaka, 21-23 December 2017, 121-124. https://doi.org/10.1109/R10-HTC.2017.8288921

[16] Bhate, S.V., Kulkarni, P.V., Lagad, S.D., Shinde, M.D. and Patil, S. (2018) IoT Based Intelligent Traffic Signal System for Emergency Vehicles. 2018 Second International Conference on Inventive Communication and Computational Technologies (ICICCT), Coimbatore, 20-21 April 2018, 788-793. https://doi.org/10.1109/ICICCT.2018.8473210

[17] Perumalla, B.K. and Babu, M.S. (2016) An Intelligent Traffic and Vehicle Monitoring System Using Internet of Things Architecture. International Journal of Science and Research (IJSR), 5, 2013-2016.

[18] Sumi, L. and Ranga, V. (2018) An IoT-Vanet-Based Traffic Management System for Emergency Vehicles in a Smart City. In: Kumar, S.P., Sambit, B., Hatzilygeroudis, L.K. and Narayan, S.M., Eds., Advances in Intelligent Systems and Computing, Volume 708, Springer, Singapore, 23-31. https://doi.org/10.1007/978-981-10-8636-6 3

[19] Zhang, H. and Lu, X. (2020) Vehicle Communication Network in Intelligent Transportation System Based on Internet of Things. Computer Communications, 
160, 799-806. https://doi.org/10.1016/j.comcom.2020.03.041

[20] Darbari, M., Yagyasen, D. and Tiwari, A. (2015) Intelligent Traffic Monitoring Using Internet of Things (IoT) with Semantic Web. In: Satapathy, S., Govardhan, A., Raju, K. and Mandal, J., Eds., Emerging ICT for Bridging the Future-Proceedings of the 49th Annual Convention of the Computer Society of India (CSI), Volume 1, Springer, Cham, 455-462. https://doi.org/10.1007/978-3-319-13728-5 51

[21] Sharif, A., Ping, J., Muhammad, L. and Sharif, I. (2019) Internet of Things Network Cognition and Traffic Management System. Cluster Computing, 22, 13209-13217. https://doi.org/10.1007/s10586-018-1722-1

[22] Thanakumar, I., Swamidason, J., Xavier, A. and Ganesh, M. (2020) Exploration of IoT Based Intelligent Traffic Management System. Engineering and Management, 4651-4658.

[23] Sona, D.R., Mendiratta, S. and Dey, D. (2017) Automatic Car Parking System with Visual Indicator along with IoT. 2017 International Conference on Microelectronic Devices, Circuits and Systems (ICMDCS), 1-3.

[24] Member, A.C., Galletta, A., Member, S. and Carnevale, L. (2017) An IoT Cloud System for Traffic Monitoring and Vehicular Accidents Prevention Based on Mobile Sensor Data Processing. IEEE Sensors Journal, 99.

[25] Das, A., Dash, P. and Mishra, B.K. (2018) An Innovation Model for Smart Traffic Management System Using Internet of Things (IoT). In: Sangaiah, A., Thangavelu, A. and Meenakshi, S.V., Eds., Cognitive Computing for Big Data Systems Over IoT, Volume 14, Springer, Cham, 355-370.

https://doi.org/10.1007/978-3-319-70688-7 15 